$2.36 \mathrm{mmol} / 1(1.6 \mathrm{mg} / 100 \mathrm{ml})$ if the 12 -hour steady-state serum lithium level was maintained at $1 \mathrm{mmol} / 1 .^{56}$ The mean dosage of Priadel required to maintain this level would be $1643 \mathrm{mg}$. Comparison of these results suggests that the peak serum lithium level would be certainly above $2 \mathrm{mmol} / \mathrm{l}$ (1.4 $\mathrm{mg} / 100 \mathrm{ml}$ ) and probably considerably above this in the patient described, as the patient was receiving a higher dosage of lithium. If the blood samples were taken just before administration of the whole dose of lithium, the peak serum lithium level would be even higher than this.

We still do not know how best to give lithium to maintain prophylaxis, but in view of the recent reports of renal damage following lithium toxicity ${ }^{7}{ }^{8}$ it is prudent to give lithium in such a way as to avoid levels in the toxic range. The majority of patients should receive lithium in at least a divided dose schedule.

S P TYRER

Queen's University,

Schou, M, et al, British fournal of Psychiatry, 1970 116, 615

${ }^{2}$ Cooper, T B, Bergner, P-E E, and Simpson, G M, American fournal of Psychiatry, 1973, 130, 601.

Amdisen, A, Danish Medical Bulletin, 1975, 22, 277. Bergner, P-E E, et al, British fournal of Pharmacology
$1973,49,328$.

Tyrer, $\mathrm{S} \mathrm{P}$, in Lithium in Medical Practice, eds $\mathrm{N}$ Johnson and $S$ Johnson, p 395. Lancaster, Medical and Technical Publishing, 1978.

Tyrer, S P, American fournal of Psychiatry, in press. Hansen, $\mathrm{H} \mathrm{E}$, et al, Proceedings of the European Dialysis and Transplant Association. London, Pitman Medical, 1977.

\section{Endometrial assessment}

SIR,-We have profound reservations abou the conclusions drawn by Dr J D Hutton and his colleagues (15 April, p 947). Endometrial cytology is notoriously difficult to assess, and whereas most experienced cytologists would be happy to differentiate between normal endometrial cells and the cells of adenocarcinoma this would not apply to the subtle changes described in cystic hyperplasia and adenomatous hyperplasia. The degree of experience required to grade these changes is considerable and could be provided only in a few centres. One can easily understand these problems, as pathologists may have difficulty in differentiating between the various hyperplasias, and they have much more tissue to examine.

The endometrial cell sampler may have a limited place as a screening procedure in postmenopausal women before they are given oestrogen therapy. In this group of patients satisfactory endometrium for histological examination is obtained in only about $12 \%$ of cases, whether the endometrium is obtained by dilatation and curettage ${ }^{1}$ or by Vabra aspiration. ${ }^{2}$

They also comment that the endometrial cell sampler is almost painless in comparison with the Vabra. Although accepting that the Vabra may be a little more painful, it is probably not significantly so. In a series of 348 Vabra aspirations performed at either Dulwich Hospital or the Birmingham and Midland Hospital for Women, $46(13 \%)$ were painless, $267(77 \%)$ had minimal or moderate pain, and only $35(10 \%)$ had severe pain. Although not strictly comparable, these results differ very little from Dr Hutton's series.

We would therefore urge caution before the endometrial cell sampler is used in the monitoring of postmenopausal patients on oestrogen therapy.

M E L PATERSON D W STURDEE

Department of Obstetrics and

Gynaecology,

Birmingham and Midland Hospital

for Women,

Birmingham

MARGARET THOM

J W W STUDD

King's College Hospital,

London SE5

1 McBride, J M, fournal of Obstetrics and Gynaecology of the British Commonwealth, 1954, 61, 691. Sturdee, D W, et al, British Medical fournal, in press.

\section{Demeclocycline in congestive cardiac} failure

SIR,-Dr D Zegers de Beyl and colleagues (25 March, p 760) demonstrated increased urine volume and sodium excretion with the use of demeclocycline in congestive cardiac failure intractable to conventional diuretics. Their explanation for this diuresis, based on experimental studies, suggests inhibition of antidiuretic hormone activity. Their data show a fall in urine osmolality commensurate with increasing urine volume, but urine osmolality remained hypertonic so that free water excretion was not apparently increased.

In congestive cardiac failure natriuresis from demeclocycline may be striking, even when urinary diluting capacity is inhibited by simultaneous "loop" diuretic administration, suggesting that natriuresis may be independent of free water excretion (see figure). Frusemide probably acts by blocking active chloride reabsorption in the thick ascending limb of the loop of Henle, ${ }^{2}$ simultaneously preventing free water formation and passive sodium reabsorption at their site. Metolazone blocks active sodium transport in the distal tubule. With combined use of frusemide and metolazone in the case shown in the figure, urine volume was maintained between 2 and 3 litres per day, presumably by inhibiting sodium reabsorption in the loop of Henle and the

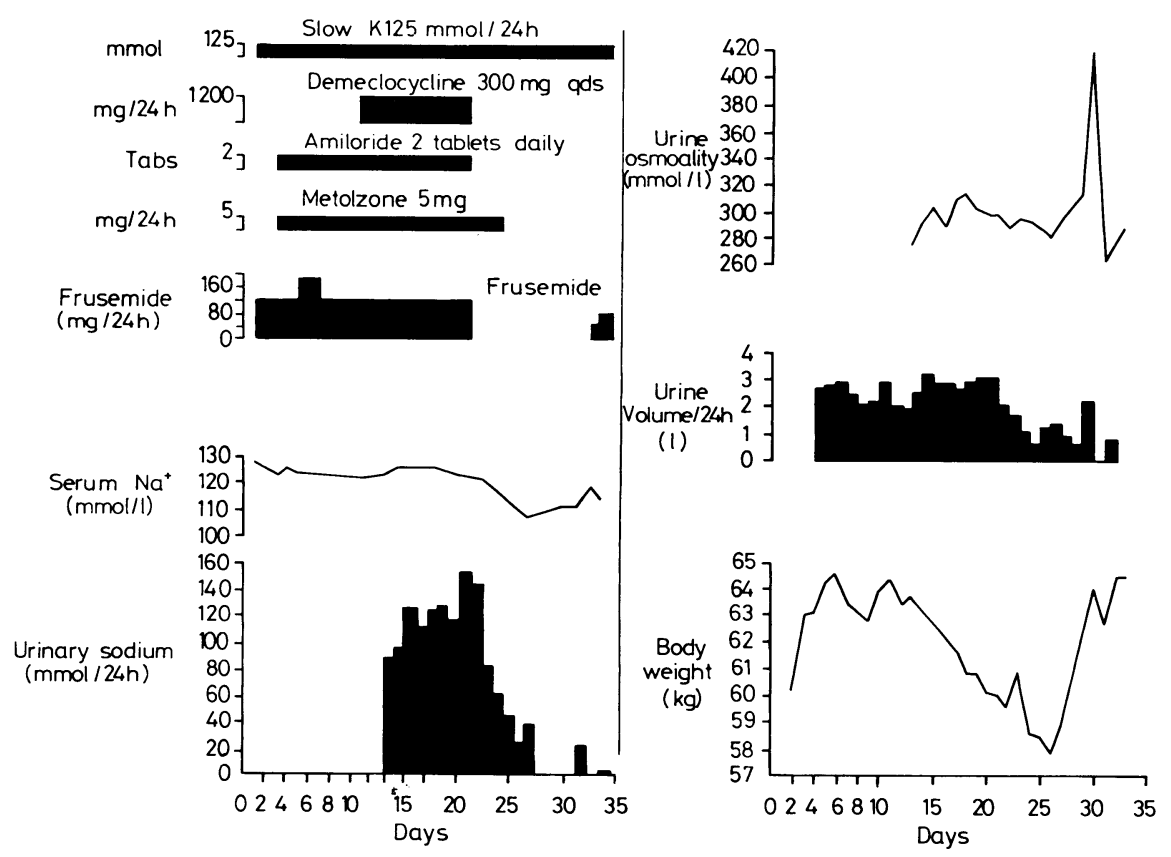

Conversion: SI to traditional units-Sodium: $1 \mathrm{mmol}=1 \mathrm{mEq}$. Osmolality: $1 \mathrm{mmol}=1 \mathrm{mosmol}$. distal tubule respectively. The addition of demeclocycline to these diuretics produced a sustained rise in urine volume, and a considerable natriuresis with associated fall in body weight. A proximal site of action for demeclocycline may be speculated on.

The $1200 \mathrm{mg}$ starting dose of demeclocycline used by Dr Zegers de Beyl may be excessive, as in our patient, a 60-year-old man with congestive heart failure, resistant oedema, and hyponatraemia. Sodium depletion resulted and was accompanied by a further fall in serum sodium concentration. Urine osmolality rose slightly during natriuresis, indicating that this was predominantly a solute diuresis. We now employ a starting dose of $150 \mathrm{mg}$ of demeclocycline per day, when conventional diuretics are simultaneously given, and increase the dose by $150 \mathrm{mg}$ every fifth day. This regimen has proved a satisfactory adjunct to diuretic therapy in intractable congestive heart failure.

R R GHOSE $\mathrm{R}$ BONSER

Singleton Hospital

Swansea ${ }^{1}$ Burg, M B, and Green, W, American fournal of

\section{Aortography in infantile coarctation}

SIR,-Adequate demonstration of the hypoplastic segment of aortic arch in infants with preductile coarctation and intraventricular septal defect frequently requires arteriotomy, with its inherent risk to subsequent growth of that limb and other complications.

The use of a balloon angiocatheter floated anterogradely from the pulmonary artery through the patent ductus arteriosus into the aorta permits the affected segment to be easily demonstrated. After inflating the balloon with carbon dioxide or dilute contrast medium so as to completely occlude the descending aorta contrast is immediately injected into the aorta proximal to the balloon and retrograde filling of the aortic arch permits angiograms of high quality to be obtained. No adverse effect has 
occurred after this procedure, which could be applied in other parts of the body. The precautions to be observed include using the shortest possible time of aortic occlusion and the use of a non-toxic medium for the inflation of the balloon in case it ruptures.

Brian Denham

\begin{abstract}
Department of Paediatrics,
Our Lady's Hospital for Sick
Children
\end{abstract}

\section{Facet joints and low back pain}

SIR,-Dr G Symonds (22 April, p 1057) asks for the evidence that low back pain with radiation to the leg can be attributed to the facet joint. This clinical syndrome has unfortunately not received the publicity it deserves. Ghormley, ${ }^{1}$ writing in 1933 on the facet joint states: "I feel not only that they are causes of sciatic pain but that they may be causes of lumbosacral pain with or without sciatic pain" and coined the term "the facet syndrome."

In a paper published in 1976 Mooney and I" not only demonstrated the patterns of referred pain but also showed reflex activity in the hamstring muscles and that limitation of straight leg raising could be produced by stimulation of a lower lumbar facet joint.

Knowledge of the basis of pain production in the lower lumbar region is still limited, but I would advise that pathological changes in the facet joint should be included in the list of differential diagnoses whenever a patient complaining of low back pain with possible radiation to the leg but without a true neurological deficit is seen.?

Southampton General Hospital,

J A ROBERTSON Southampton

Ghormley, R K, fournal of
Association, 1933, 101, 1773. Association, 1933, 101, 1773. Clinical Orthopaedics, 1976, $115,149$. ${ }^{3}$ Badgley, C E, fournal of Bone and foint Surgery, 1941,
23, 481.

SIR,-May I be permitted to rise to the bait offered by Dr G Symonds (22 April, p 1057) when he implies that lesions of the facet joints are not common causes of lumbago and sciatica? I do so in support of your leading article (1 April, p 808) as I believe that much standard medical education in the decades 1940-70 overplayed the large role of the intervertebral disc in the production of lumbar problems so that many doctors have found difficulty in helping patients with lumbago and sciatica due to other causes. Since the group with such problems is large and their problems can be diminished greatly by education alone I believe it to be helpful to understand why such a group exists and how they can be helped.

The basic work of Kellgren ${ }^{1-3}$ in demonstrating the effects of injury to various spinal structures in the production of backache and pain down the lower limb indicated that damage to the intervertebral joints could produce backache and referred leg pain (but not altered sensibility, loss of power, or altered reflexes).

The structure of the intervertebral joints differs in no fundamental respect from that of any synovial joint such as the knee joint-that is, there is the usual articular cartilage and innervated synovial line and joint capsule. These joints suffer from degenerative arthritis in the same way as the knee joint. The degenerative changes show radiographically and are very easily seen in the post-mortem room or the operating theatre. The response of the intervertebral joints to injury is similar to that seen so commonly in the knee joint in middle-aged men, in whom a minor twist may produce discomfort followed by an ache and swelling within a few days and tenderness over the medial joint line and a slow spontaneous recovery. Where the joints differ is that the back joints are surrounded by very strong muscles whose protective spasm may of itself produce pain and load the sprained joints and increase discomfort arising from them.

The production of injury to the worn back joints is similar to the production of injury in any other joint-either a specific individual strain or, commonly, the postural strains of standing or sitting badly. Anything which decreases the controlling muscle supports of the back, belly, and buttock (such as fatigue) will predispose to strain, as will anything which increases lumbar lordosis (such as overweight or high heels).

In a letter there is insufficient scope for a full explanation of the treatment of acute sprains or of the chronic sprains of these joints, but the fundamental principles differ in no important respect from those which most people would apply to treatment of a sprained ankle. These include: (1) anything which hurts does harm; and (2) all painless movements do good.

To prevent recurrences I suggest treating the patients by "organised neglect." This constitutes reminding them that "brave patients do badly" and "persistent cowards do well"the persistent coward keeps in training by painless exercise and avoids unreasonable lifting or postural stresses. The "neglect" element is designed to eliminate the fear instilled in so many that they have a mysterious disc problem instead of the very common, indeed invariable, degenerative problem of the second half of life.

A H G MURLEY

Cambridge

Kellgren, J H, Clinical Science, 1938, 3, 175.

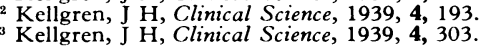

Vacuum pipelines for anaesthetic pollution control

SIR,-Dr B M Wright (8 April, p 918) is critical of the reasons advanced by $\mathrm{Dr} M$ Rosen (21 January, p 176) and the DHSS's health circular $\mathrm{HC}(76) 38$ deprecating the use of piped vacuum to scavenge waste anaesthetic gases. We are not reassured by the arguments he advances, as we believe that the use of piped vacuum for this purpose introduces a potential hazard to the patient. The existence of this hazard has been pointed out in the relevant health circular. It results from the great disparity between the negative pressure in the piped vacuum system when compared to that required for safe scavenging of anaesthetic gases. The vacuum in the pipeline is approximately 1000 times in excess of the requirement for scavenging and this means that there is a very onerous safety requirement for the design and use of any equipment which limits the suction at the scavenging point. A perforated hood ${ }^{1}$ has been suggested, but we feel that this offers an inadequate margin for patient safety. If such a device is used widely, eventually, either by accident or by design, some or all of the holes will become obstructed; one possibility for such obstruction is presented by the increasing use of impervious plastic surgical drapes. The result of such obstruction will be that a considerable negative pressure will be applied to the patient's airway, the deleterious effects of which have been recognised in relation to endotracheal suction. ${ }^{2}$

An alternative system for active scavenging using existing equipment is to connect to the extract side of the theatre ventilation system at a point where it is not possible to generate a greater negative pressure than $0.5 \mathrm{~cm} \mathrm{H}_{2} \mathrm{O}$. When this is used in conjunction with a suitable safety block ${ }^{3}$ to provide pressure relief and a visual indication of the functioning of the whole extract system, safe, practical, and inexpensive scavenging is possible. In most British operating theatres a suitable point for connection to the theatre extract can be found in relation to the ducting connected to the mechanical extract point provided in accordance with Hospital Building Note 26 (1967) in each anaesthetic room. As this mechanical extract is specifically provided "because of the presence of gases" no problems should arise from such a connection. In the very few theatres with a recirculating system careful siting will be needed of the scavenging connection to the ducting which carries that percentage of the airflow which is not recirculated. It is hoped that in the design and installation of theatre ventilation systems in the future suitable points for connecting scavenging systems will be provided not only in the anaesthetic room but also in the operating theatre.

D W Bethune J M Collis

Anaesthetic Departments,
Papworth and Addenbrooke's

Hospitals,

Hospitals,
Cambridge

1 Davenport, H T, et al, British Medical fournal, 1976 , 2, 1219.

osen, $M$, and Hillard, E K, British fournal of Anaesthesia, 1960, 32, 486.
Bethune, D W, Collis, J $\mathrm{M}$, and Latimer, R D, Anaesthesia, 1976, 31, 1254 .

\section{Bleeding gastric erosion after oral} zinc sulphate

SIR,-I was interested to read the report by Dr Ray Moore (25 March, p 754) of a case of bleeding gastric erosion following oral zinc sulphate and the comments by Drs $M$ Molokhia and Benjamin Portnoy (29 April, p 1145).

Frommer in $1975^{1}$ carried out a doubleblind trial on patients with benign gastric ulcer. Ten were given zinc sulphate $220 \mathrm{mg}$ three times a day and eight were given a placebo. After three weeks patients taking the zinc sulphate had an ulcer healing rate three times that of the patients taking the placebo, and more patients in the zinc sulphate group achieved complete healing. The hydrochloric acid content in the gastric juice is high in many patients with gastric ulcer, especially if the ulcer is near the pylorus and pylorospasm is present, so that the likelihood of zinc chloride being formed by the action of the hydrochloric acid on the zinc sulphate is greater in ulcer patients than in the normal population.

Although the numbers are small, these findings appear to show that, in spite of the 